\title{
Electrochemical Biosensor Based on Hemoglobin and Titanate Nanotubes Modified Electrode and its Application
}

\author{
Wenju Weng ${ }^{1}$, Juan Liu ${ }^{1}$, Chunxiao Yin ${ }^{1}$, Hui Xie ${ }^{2}$, Guiling Luo ${ }^{2}$,Wei Sun ${ }^{2}$, Guangjiu Li ${ }^{1, *}$ \\ ${ }^{1}$ Key Laboratory of Optic-electric Sensing and Analytical Chemistry for Life Science of Ministry of \\ Education, College of Chemistry and Molecular Engineering, Qingdao University of Science and \\ Technology, Qingdao 266042, P R China \\ ${ }^{2}$ Key Laboratory of Laser Technology and Optoelectronic Functional Materials of Hainan Province, \\ Key Laboratory of Functional Materials and Photoelectrochemistry of Haikou, College of Chemistry \\ and Chemical Engineering, Hainan Normal University, Haikou 571158, P R China \\ *E-mail: ligj@qust.edu.cn
}

doi: $10.20964 / 2019.05 .60$

Received: 1 February 2019 / Accepted: 5 March 2019 / Published: 10 April 2019

\begin{abstract}
An electrochemical biosensor based on hemoglobin $(\mathrm{Hb})$ and titanate nanotubes (TNTs) modified carbon ionic liquid electrode (CILE) was prepared with direct electrochemistry and electrocatalysis of $\mathrm{Hb}$ investigated. The morphology and structure of TNTs was analyzed by field emission scanning electron microscopy and transmission electron microscopy. UV-Vis and FT-IR spectra confirmed that $\mathrm{Hb}$ maintained the natural conformation with TNTs. A pair of enhanced reversible redox peak could be observed on Nafion/Hb/TNTs/CILE, indicating that the positive effects of TNTs to the electron transfer. The electrochemical parameters of $\mathrm{Hb}$ on the modified electrode were calculated with the number of electron transfer $(n)$, the charge transfer coefficient $(\alpha)$ and the electrode reaction rate constant $\left(k_{s}\right)$ obtained as $1.18,0.478$ and $0.85 \mathrm{~s}^{-1}$, respectively. The electrochemical sensor was applied to investigate the electrocatalytic performance to trichloroacetic acid (TCA) and nitrite with excellent ability.
\end{abstract}

Keywords: hemoglobin; titanate nanotubes; direct electrochemistry; electrocatalysis.

\section{FULL TEXT}

(C) 2019 The Authors. Published by ESG (www.electrochemsci.org). This article is an open access article distributed under the terms and conditions of the Creative Commons Attribution license (http://creativecommons.org/licenses/by/4.0/). 